\title{
PRESENCIA DEL RELATO FANTÁSTICO DE MAUPASSANT EN ALGUNOS CUENTOS DE EMILIA PARDO BAZÁN
}

\author{
por \\ CRISTINA PÁTIÑO EIRIN
}

Entre los numerosos géneros cultivados por la pluma de Emilia Pardo Bazán destaca, por la maestría y frecuencia de su composición, el del cuento. Un libro reciente de Rolf Eberenz atribuye a la autora de Los Pazos de Ulloa la realización de lo que llama "la forma canónica del cuento naturalista"1 ${ }^{\prime \prime}$. Dejando a un lado, por ahora, la calificación de sus cuentos desde el punto de vista literario - y se discute también con fundamento su ortodoxia naturalista en el campo de la novela - sí hemos de convenir que Pardo Bazán fue uno de los autores del siglo XIX que más y mejor trabajaron por el ennoblecimiento del cuento como género. Esta ardua tarea se había iniciado en tiempo de Fernán Caballero, pero necesitaba sin duda la aportación definitiva de las mejores plumas de la llamada "Generación de la Restauración" para afianzarse para siempre.

En 1904, en el prólogo a los Cuentos de Fernanflor, Pérez Galdós recordará aquellos primeros intentos de hacer del cuento una fórmula de expresión literaria válida y reconocida por la crítica y el público. Don Benito recurría allí a una explicación de carácter lingüístico para justificar la ausencia de cuentos en su país:

"La introducción del cuento en nuestros métodos literarios de trabajo no era empresa fácil, pues los escritores de acá propendiamos

\footnotetext{
${ }^{1}$ Cfr. EBERENZ, Rolf, Semiótica y Morfología textual del cuento naturalista (Emilia Pardo Bazán, Leopoldo Alas "Clarin", Vicente Blasco Ibáñez), Madrid, Gredos, 1989, p. 11.
}

"CUADERNOS DE ESTUDIOS GALLEGOS", Tomo XLI, Fascículo 106, Santiago 1993-94. 
a las longitudes y a dormirnos sobre las cuartillas, sin duda porque la gran correa de nuestro idioma facilita el fraseo, el desarrollo verbal, y éstos desatan, sin sentirlo, la sarta analítica de las ideas ${ }^{\prime 2}$.

Eran los tiempos del folletín y la novela por entregas. Las dificultades para vivir de la literatura impelían a la mayoría de los escritores a enviar con regularidad sus trabajos a revistas y periódicos que los editaran diaria o semanalmente para un público ávido de aventuras novelescas y lances entretenidos.

El cuento venía a cubrir a la perfección ese hueco. Además de ser de poca extensión y tener cabida en el espacio reducido con que se contaba en las publicaciones periódicas, poseía otra ventaja respecto al ensartado indefinido de entregas de novela: empezaba y terminaba allí mismo. El lector podía quedarse tranquilo tras su lectura, sin esperar a comprar o recibir el número siguiente de la revista o a que apareciese debajo de su puerta la continuación del folletín. Una vez introducido en los hogares, el cuento llegó a hacerse muy popular y, como constata la propia Pardo Bazán, se vendía muy bien ${ }^{3}$.

Desde el punto de vista estructural el cuento permite al escritor gran capacidad de maniobra. En el prólogo a Cuentos de amor (1898) doña Emilia afirma sin ambages:

"No hay género más amplio y libre que el cuento".

Pero hay otra cualidad interna del cuento que se ajusta más todavía al método creativo de nuestra escritora. Nos referimos a la capacidad que tiene el cuento de intensificar un momento preciso. La poca extensión obliga a condensar enormemente aquello que se pretende contar. De ahí que Pardo Bazán establezca una analogía entre la poesía y el cuento:

${ }^{2}$ Vid. SHOEMAKER, William H., Los prólogos de Galdós, México, Ediciones de Andrea, 1962, p. 71.

${ }^{3}$ Así lo dice en carta a José Yxart, fechada el 27 de Diciembre de 1883. Vid. TORRES, David, "Veinte cartas inéditas de Emilia Pardo Bazán a José Yxart", Cuadernos de Estudios Gallegos, Tomo XXI, p. 428, (también recogido en el Boletín de la Biblioteca de Menéndez Pelayo, LIII, 1977):

"Mucho me alegraría de que esa empresa de Arte y Letras editase mi tomo de Cuentos. ¿Qué autor no apetece ver su prosa en tan bonita forma? Yo creo que para la empresa el libro no sería de los menos útiles y vendibles, no por lo que yo valga que es bien poco sino porque los cuentos en general se venden bien".

${ }^{4}$ PARDO BAZÁN, Emilia, Obras completas, Tomo I, Estudio preliminar, notas y preámbulos de F.C. Sáinz de Robles, Madrid, Aguilar, 1973 (4ª ed.), p. 1214.

"CUADERNOS DE ESTUDIOS GALLEGOS", Tomo XLI, Fascículo 106, Santiago 1993-94. 
"uno y otro son rápidos como un chispazo, y muy intensos porque a ello obliga la brevedad, condición precisa del cuento. Cuento original que no se concibe de súbito..."

He ahí cómo explica la autora de más de seiscientos cuentos la génesis de estos pequeños relatos en los que abordó los asuntos más diversos. En este trabajo nos centraremos en aquellos que, o bien por lo llamativo del tema elegido o bien por la importancia concedida a su función simbólicofantástica, la aproximan de modo inequívoco a uno de los más espléndidos y genuinos representantes del cuento fantástico en la literatura francesa: Guy de Maupassant ${ }^{6}$.

Desde el punto de vista temático es significativa la proximidad que podemos establecer entre el cuento de Pardo Bazán titulado El mausoleo y el de Maupassant Décoré . El de la autora gallega pertenece a la recopilación que tituló Sud-Exprés (1902); Décoré había aparecido en $1883^{8}$. Resulta curioso que el arranque de ambos cuentos sea tan parecido. En ambos casos el narrador asienta un principio de carácter general que origina la expansión narrativa subsiguiente. Es lo que R. Eberenz denomina "baliza temática"s. Veamos ambos incipit:

"Esto de las ambiciones humanas tiene mucho que observar. Hay ambiciones generales; hay otras individuales, extrañas, todas

\footnotetext{
${ }^{5}$ Ibidem.

${ }^{6} \mathrm{R}$. Eberenz, en su libro ya citado, pone también en relación los cuentos de temática gallega de Pardo Bazán con los relatos de Maupassant sobre el mundo rural de Normandía. En este sentido afirma que la visión de la autora coruñesa no es tan implacable y la tónica general de sus cuentos del terruño dista del nihilismo del francés. Según Eberenz, Pardo Bazán mantiene todavía la ilusión burguesa y evita juzgar el mecanismo de la sociedad. Vid. Op. cit., p. 25.

${ }^{7}$ Proximidad ya percibida por Eberenz en su obra (p. 105):

En El mausoleo -la historia de un personaje insignificante que cifra la razón última de su vida en la obtención de un mausoleo - hay analogía con Décoré, de Maupassant: ambos protagonistas logran aparentemente un absurdo propósito, pero acaban descubriendo que han sido engañados en otro orden de cosas".

Veremos cómo nuestra interpretación difiere un tanto de esta.

${ }^{8}$ Firmado por Maufrigneuse, pseudónimo entonces utilizado por Maupassant. Décoré apareció en el Gil Blas el 13 de Noviembre de 1883. La edición que manejamos es la siguiente: MAUPASSANT, Guy de, Contes et Nouvelles, París, Gallimard, 1974, pp. 19651070.

${ }^{9}$ Op. cit., p. 59.
}

"CUADERNOS DE ESTUDIOS GALLEGOS", Tomo XLI, Fascículo 106, Santiago 1993-94. 


$$
\text { vanas" }^{\prime \prime}(\mathrm{PB})^{10} \text {. }
$$

"Des gens naissent avec un instinct prédominant, une vocation ou simplement un désir éveillé, dès qu'ils commencent à parler, à penser" (Maup.) ${ }^{11}$.

Ambos relatos aparecen introducidos directamente por un narrador, sin que se recurra al mecanismo del marco conversacional. De ahí que pertenezcan a lo que J. Paredes, máximo compilador de los cuentos de Pardo Bazán, agrupa bajo la denominación de "cuentos directos". Una vez establecido el principio general se pasa a comprobar su aplicación en un caso individual: el de don Probo Gutiérrez López, empleado subalterno, en la narración pardobazaniana, el de M. Sacrement, en el cuento de Maupassant. La prehistoria de ambos personajes se perfila desde el principio:

"Desde niño había fantaseado que sus despojos esperasen el Juicio Final encerrados en un mausoleo suntuoso, erigido en el cementerio de su ciudad natal, Repoblada" (PB) ${ }^{12}$.

"M. Sacrement, n'avait, depuis son enfance, qu'une idée en tête, être décorè" (Maup.) ${ }^{13}$.

El narrador primopersonal de Pardo Bazán se muestra más elocuente que el de Maupassant, se preocupa de proporcionar más datos puntuales - localización geográfica, categoría profesional de su protagonista-; desde un principio toma las riendas del relato con ánimo de emitir incluso ciertos juicios de valor. Así, el cementerio de Repoblada se le antoja "ejemplar de lo antiestético y antipoético de las construcciones modernas ${ }^{\prime 14} \mathrm{y}$, más adelante, después de describir la capilla con pormenor asociable a la necrofilia finisecular, añade sin rodeos: "con todo esto, Probo Gutiérrez anhelaba ocupar en el cementerio más feo del mundo un lugar de preferencia $^{\prime \prime 15}$. Por el contrario, el narrador de Maupassant se entretiene más en la evolución vital de su personaje: cómo se casa con una joven rica y

${ }^{10}$ PAREDES, Juan, (ed.), Pardo Bazán, E., Cuentos completos, La Coruña, Fundación "Pedro Barrié de la Maza. Conde de Fenosa", 1990, Tomo III, pp. 76-78. Esta será la referencia cada vez que remitamos a un cuento de Pardo Bazán.

${ }^{11}$ Maup., Op. cit., p. 1064.

${ }^{12}$ Ibidem.

${ }^{13}$ Ibidem.

${ }^{14}$ Ibidem.

${ }^{15}$ Ibidem.

"CUADERNOS DE ESTUDiOS GALLEGOS", Tomo XLI, Fascículo 106, Santiago 1993-94. 
cómo conoce a un diputado ministrable. El personaje aparece enfocado desde su propio interior. No faltan muestras de discurso directo, mediante las cuales accedemos a su pensamiento. Es "su idea" la que actúa como hilo conductor del relato:

"Mais la pensée entrée aux premiers jours de sa vie dans la tête de M. Sacrement, ne le quittait plus et il souffrait d'une façon continue de n'avoir point le droit de montrer sur sa redingote un petit ruban de couleur"16.

Esas ideas son contadas muy desde fuera, por un narrador que observa y anota. Incluso cuando oímos la voz interior de M. Sacrement, su discurso se delimita con signos de puntuación que marcan la exactitud de la transcripción de su pensamiento:

"Chaque fois que M. Sacrement apercevait un groupe de vieux messiers à cheveux blancs arrêtés au milieu du trottoir, et gênant la circulation, il se disait: "Voici des officiers de la Légion d'honneur" Et il avait envie de les saluer"17.

El narrador de Pardo Bazán se implica mucho más en aquello que cuenta, hasta el punto de mostrar cierta incomprensión hacia el "inexplicable interés por la construcción de cenotafios y panteones, la colocación de tapias y rejas" de que hace gala su personaje. Analiza la obsesión de don Probo:

"Era la sed de inmortalidad que a veces acomete a los seres predestinados al olvido, los cuales buscan la supervivencia en un afecto, en un corazón y, a falta de eso, en unas piedras amontonadas. No tenía ni hondos cariños ni íntimas amistades: solterón sin relieve social ni sentimental, tímido y torpe con las mujeres, indiferente a todos, cuando desapareciese de entre los vivos sería como brizna de paja un día de aire. Acaso esta consideración, siempre mortificadora para el amor propio del aniquilamiento absoluto, explique el sueño monumental de don Probo. El olvido es forma del no ser, y él, don Probo, quería perpetuarse en granito y en bronce, ya que no en hijo, en libro, en amor, en hecho alto e ilustre"l18.

Vemos cómo se nos explica "ese inexplicable interés". Pero hay que decir que Pardo Bazán emplea una primera persona, lo cual confiere a la

\footnotetext{
${ }^{16}$ Maup., Op. cit., p. 1065.

${ }^{17}$ Maup., Op. cit., p. 1066.

${ }^{18}$ PB, Op. cit., p. 77.
}

"CUADERNOS DE ESTUDIOS GALLEGOS", Tomo XLI, Fascículo 106, Santiago 1993-94. 
instancia narrativa una mayor credibilidad, ya que se trata de un narrador testigo que puede hacer aflorar su superioridad respecto a un ser que considera digno de compasión y sin que ello vaya en detrimento de la verosimilitud. El buen don Probo, con su raída levita y su sombrero anticuado, se nos hace simpático a nosotros, lectores. Su desgraciado fin - debido a una pulmonía - y su entierro sin acompañamiento, su tumba exenta - un nicho sin lápida de mármol — acentúan esa impresión de lástima como la que nos inspiran tantos personajes marginados que la vida zarandea en los relatos de "Clarín". El fin de don Probo será trágico. Cuando su hermano consiga elevar un mausoleo en su honor el cuerpo que allí se traslade será el de un usurero, cuyo cadáver fue confundido con el de don Probo el día de su entierro. Este final sorpresivo se anunciaba ya. La morosidad con que se describe el monumento funerario y los detalles de su construcción $^{19}$ actúa como técnica dilatoria que da al final último mayor fuerza. Una fuerza a la que el narrador no es ajeno, como lo demuestran los incisos ${ }^{20}$.

El cuento de Maupassant hace bascular todo el peso del relato sobre la sed de grandeza de M. Sacrement, su ansia inextinguible de ser condecorado con la Legión de Honor $^{21}$. No es un personaje de mezquina extracción social, como don Probo, además, su idea fija resulta un tanto ridícula porque carece de toda espiritualidad. Pero el narrador se guarda bien de calificar a su personaje. Es su actuación, sus palabras o sus pensamientos - siempre en discurso directo debidamente entrecomillado- los que nos

\footnotetext{
${ }^{19}$ PB, p. 78:

"Seis meses después llegaba a la ciudad el hermano tronera. La antojadiza suerte le había sonreído (...). Quizá era este deseo de honores póstumos una propensión característica de la casta. Ello es que el jugador soñaba lo mismo que el formal y metódico, y se traía los planos, el presupuesto, el arquitecto, hasta operarios de Italia. Tratábase de un monumento original, destinado a chafar a los restantes, en que se mezclaban los jaspes de color, las serpentinas, los vidrios polícromos, hasta la cerámica, para una creación modernista sorprendente, donde se agotaba el tema de los letreros en asirio, la amapola somnifera, los cipreses formando procesión de obeliscos, los jirasoles (sic), emblema de inmortalidad, y los lotos, emblema del sueño y del nirvana".

${ }^{20}$ Ibidem:

"Ya terminado, sin faltarle requisito vino el fundador e hizo trasladar a él solemnemente el cuerpo... del usurero, que ocupaba el nicho destinado a don Probo; mientras los restos de éste -frustrado allende la tumba en su perenne anhelo- continuaron disolviéndose olvidados en humilde nicho".

${ }^{21}$ Maup., p. 1070.
}

"CUADERNOS DE ESTUDIOS GALLEGOS", Tomo XLI, Fascículo 106, Santiago 1993-94. 
hacen tener esa impresión. El final, también en forma de latigazo - $\mathrm{M}$. Sacrement es finalmente condecorado gracias a "servicios especiales de su mujer" al diputado- es escueto y ambiguo:

"Huit jours plus tard l'Officiel annoçait que M. Sacrement était nommé chevalier de la Légion d'honneur, pour services exceptionnels' ${ }^{\prime 22}$

La lástima que se deriva de este final ya no es compasión ni tristeza porque el personaje consigue ver realizado su anhelo a costa de su honestidad.

Dos cuentos muy semejantes también desde el punto de vista temático son los titulados Consuelo ${ }^{23}$ y L'Infirme ${ }^{24}$. Esta vez Maupassant emplea un narrador en primera persona. La credibilidad del inválido de guerra Henri Bonclair se hace patente a lo largo de su relato a un compañero de viaje - el narrador - en el tren que lo conduce a visitar a los hijos de la mujer que amó. Esa conversación le lleva a recordar cómo ocurrió todo, cómo no quiso exigir a su novia el sacrificio de casarse con un inválido: "Je n'accepte pas le renoncement d'une femme à toute une vie ${ }^{125}$. Por su parte, Pardo Bazán moldea el mismo argumento haciendo hincapié en ciertos aspectos que no aparecen en Maupassant. Así, un narrador en tercera persona nos suministra muchos más datos acerca del noviazgo de Teodoro, aunque también se vierten indicios del final: "la boda se celebraría en mayo, si no se atravesaba ningún obstáculo en el camino de la felicidad de los novios ${ }^{126}$. La operación sufrida es descrita con minucia:

"Teodoro resistió la operación con los ojos abiertos, y vio cómo el bisturí incidía su piel [sic] y resecaba sus músculos, cómo la sierra mordía en el hueso hasta llegar al tuétano y cómo su pierna derecha, ensangrentada, muerta ya, era llevada a que la enterrasen... Y no exhaló un grito ni un gemido; tan sólo en el paroxismo del dolor, tronzó con los dientes el cigarro que chupaba"27.

\footnotetext{
${ }^{22}$ Ibidem

${ }^{23}$ Cuentos de amor, Obras completas, Tomo XVI, 1898. En Paredes, Tomo I, pp. 326328.

${ }^{24}$ Maup., pp. 1045-1050. Apareció por primera vez en Le Gaulois, el 21 de Octubre de 1888.

${ }^{25}$ Maup., p. 1049.

${ }^{26} \mathrm{~PB}$, p. 327

${ }^{27}$ Ibidem.
}

"CUADERNOS DE ESTUDIOS GALLEGOS", Tomo XLI, Fascículo 106, Santiago 1993-94. 
Es frecuente en Pardo Bazán la descripción médica, que muchos asociaron al naturalismo por la tendencia visible en la autora coruñesa a insertar en la narración detalles fisiológicos:

"Según el cirujano, la operación había salido divinamente. No hubo supuración ni calentura; cicatrizó el muñón bien y pronto, y Teodoro no tardó en ensayar su pierna de palo, una pata vulgar, mientras no podía encargar a Alemania otra hecha con arreglo a los últimos adelantos..." ${ }^{128}$.

Aparece también en este cuento el uso del estilo indirecto libre, modalidad narrativa asociada asimismo a la novela experimental zoliana precisamente por su neutralidad, que la aproxima a la buscada objetividad impasible. Así, al final del relato percibimos la conciencia dolorida de Teodoro:

¿¿Por qué no estaba ella allí para asistirle, y acompañarle, endulzar sus torturas? ¿Cómo iba a resistir hasta la carta siguiente, donde él participase su mejoría? (...) Ya no era el gallardo oficial de esbelta figura y andar resuelto y brioso. Era un inválido, un pobrecido inválido, un infeliz inútil ${ }^{\prime 29}$.

Además de los señalados, otros cuentos de Pardo Bazán dejan ver concomitancias temáticas con relatos de Maupassant. Es el caso de Vivo retrato (1893) y $M$. Jocaste (1883), que abordan el tema del incesto. En el cuento de Maupassant el narrador lo consiente y apoya; en el relato pardobazaniano se pone el acento, por el contrario, en la venganza de una mujer ofendida por el amor ilimitado de su marido hacia su madre. La influencia temática del autor de Mademoiselle Fifi sobre la escritora gallega puede rastrearse asimismo en la similitud de argumento entre cuentos como La bicha y Ma femme o Tiempo de ánimas y Auprès d'un mort, por ejemplo.

Existe un segundo nivel de concomitancias entre los cuentos de Pardo Bazán y los debidos a la pluma de Maupassant. Nos referimos a aquellos que presentan una función simbólica asociada a la componente fantástica. Así sucede en Eximente y La calaver ${ }^{30}$, de Pardo Bazán, y las semejanzas que presentan con $L u i$ ? y las sucesivas versiones que de él se derivan en

\footnotetext{
${ }^{28}$ Ibidem.

${ }^{29}$ Ibidem.

${ }^{30}$ Paredes, Tomo II, pp. 379-382. Interiores, Blanco y Negro, núm. 714, 1905.
}

"CUADERNOS DE ESTUDIOS GALLEGOS", Tomo XLI, Fascículo 106, Santiago 1993-94. 
las cuales Maupassant reelabora el germen fantástico de ese cuento ( $L e$ Horla 1 y Le Horla 2 o versión definitiva) ${ }^{31}$.

Eximente, cuento publicado en los albores del siglo XX, es un buen ejemplo de lo que se llamó a partir de Gómez de Baquero, "Andrenio", la segunda manera de Pardo Bazán. En efecto, en este cuento aflora ya sin cortapisas el análisis psicológico y espiritual del personaje, Federico Molina. Aparece el mismo año en que publica en libro La Quimera, novela en que se consagra definitivamente el predominio de ese análisis sobre el que la crítica y la propia autora venían considerando característico del naturalismo ${ }^{32}$.

El cuento se introduce con unas palabras en las que el narrador en primera persona trata de explicar el suicidio del personaje a partir de la lectura de su diario:

"Así pude penetrar en el espiritu del suicida, y creo que nadie traducirá sino como yo las traduje las indicaciones que extracto coordinándolas" ${ }^{\prime 33}$.

El recurso es viejo y de raigambre cervantina, pero constituye sin duda una buena coartada para el narrador y denota una preocupación formal.

En el caso de Maupassant nos centraremos en el primer relato, Lui?, que culminarán las dos redacciones sucesivas de Le Horla. En los tres cuentos la modalidad narrativa es primopersonal, si bien en Lui? tiene forma de carta y en las dos versiones de Le Horla de diario y de discurso del enfermo a los médicos.

Todos estos cuentos ponen en escena el miedo intrínseco e inexplicable ante algo desconocido y misterioso. Este es sin duda el gran argumento de una de las obras magistrales que la posteridad asocia al nombre de Maupassant: Le Horla. Lo curioso del cuento del autor de La Maison Tellier es que quien narra trata de explicar desde el ángulo de la lógica y la racionalidad todo lo que sus sentidos experimentan: visiones, alucinaciones, sonidos extraños... También Pardo Bazán hace que su personaje analice introspectivamente lo que le sucede:

\footnotetext{
${ }^{31}$ Maup., pp. 869-875: Lui? apareció en el Gil Blas el 3 de Julio de 1883. Le Horla 1 se publicó en el Gil Blas del 27 de Octubre de 1886 (Maup., Op. cit., Tomo II, pp. 822830) y la versión definitiva, Le Horla 2, salió en 1887 (Maup., Op. cit., Tomo II, pp. 913938).

${ }^{32}$ Ya en novelas como Una cristiana-La prueba o La piedra angular se había iniciado esa segunda manera.

${ }^{33}$ PB, p. 380.
}

"CUADERNOS DE ESTUDIOS GALLEGOS", Tomo XLI, Fascículo 106, Santiago 1993-94. 
"Se me figura que el origen de esto ha sido la mala costumbre de leer de noche, en cama, a altas horas ${ }^{134}$.

Aunque la anécdota que da pie al personaje de Maupassant a escribir a su amigo - su matrimonio, para evitar estar solo - no aparece en el relato de Pardo Bazán, el fondo del cuento y varios detalles similares apuntan a una posible influencia directa del autor francés sobre doña Emilia, siempre atenta y ávida lectora de la literatura de aquel país. Así, los protagonistas de ambos cuentos viven en habitaciones confortables y cómodas que de ningún modo incitan a pensamientos tétricos. Federico Molina vive en un barrio tranquilo de Madrid, en una habitación "bonita, sin rinconadas ni cortinajes, llena de luz", con colores alegres y cuadros serenos en las paredes. El innominado personaje de Le Horla también está rodeado de un ambiente nada favorable a los fantasmas: "Ma demeure est vaste, peinte en blanc à l'extérieur, jolie, ancienne, au milieu d'un grand jardin planté d'arbres magnifiques..." ${ }^{135}$.

A pesar de ello, Federico Molina reconoce:

";tengo miedo!..., un miedo terrible, un miedo que me impide respirar, sosegar y vivir ${ }^{136}$

Confrontemos con el texto de Lui?:

"Eh bien! j'ai peur de moi! j'ai peur de la peur; peur des spasmes de mon esprit qui s'affole, peur de cette horrible sensation de la terreur incompréhensible ${ }^{137}$.

En ambos casos se trata de alguien que acecha:

"Y esto es lo extraño: - escribe F. Molina-me encuentro en compañia de alguien, no sé de quién, pero de alguien que se instala allí, a mi lado, tan próximo, que me parece escuchar el ritmo de su respiración y advertir cómo su sombra se desliza suave, fugaz, por la blanca pared frontera" ${ }^{\prime 38}$.

El personaje de Maupassant emplea el pronombre indefinido francés on para referirse a ese ser:

"On avait bu toute l'eau que j'avais vue deux heures plus tôt"139.

\footnotetext{
${ }^{34}$ Ibidem.

${ }^{35}$ Le Horla 1, p. 823.

${ }^{36} \mathrm{~PB}$, p. 381.

${ }^{37}$ Lui ?, p. 870.

${ }^{38}$ Ibidem.

${ }^{39}$ Le Horla 1, p. 824.
}

"CUADERNOS DE ESTUDIOS GALLEGOS", Tomo XLI, Fascículo 106, Santiago 1993-94. 
Se trata de alguien, de una persona: "Il existait près de moi un être individuel qui m'avait hanté, puis m'avait quitté; et qui revenait ${ }^{\prime \prime 40}$. Lo llamará $\mathrm{Horla}^{41}$.

Federico Molina no lo nombra de ninguna forma pero lo siente a sus espaldas, con su mano fría y marmórea ${ }^{42}$ y su respiración. La elaboración del caso patológico es mucho menor que en Maupassant, que llega, en la versión definitiva de Le Horla (1887), a expresar como no se había hecho antes el escalofrío que produce lo desconocido e indeterminado y a plantear el problema de su personaje con total precisión:

"D'où viennent ces influences mystérieuses qui changent en décourageent notre bonheur et notre confiance en détresse? On dirait que l'air invisible est plein d'inconnaissables Puissances, dont nous subissons les voisinages mystérieu"43.

Si cotejamos los finales, vemos cómo en Lui? el personaje salva su vida casándose - remedio que con la perspectiva del desarrollo ulterior del argumento en las dos versiones del Horla resulta cuando menos irrisorio-. En Le Horla 1 el final queda abierto, los doctores se preguntan sobre la naturaleza de la locura del personaje narrador. En la versión definitiva del cuento, Le Horla 2, el suicidio del atormentado personaje parece inminente:

"Alors... alors... il va donc falloir que je me tue, moi!..."44.

Así es como concluye el cuento de Pardo Bazán, que remata con una apreciación debida al narrador inicial, a quien debemos la coordinación del diario:

"Sin duda,el miedo insuperable hizo su oficio y Federico Molina no disparó contra su sombra"45.

J. Paredes hace notar la semejanza palmaria de Eximente con Le Horla. Aquí hemos visto también su grado de parentesco con las dos versiones que antecedieron a ese relato: Lui? y Le Horla 1. Constatamos que existe sobre todo una analogía temática y que el grado de elaboración de ese

\footnotetext{
${ }^{40}$ Ibidem, p. 826.

${ }^{41}$ No se conoce con exactitud el origen del término, que muchos asocian a la expresión hors là -fuera de este mundo-.

${ }^{42}$ Posible eco del mito de Don Juan y el convidado de piedra, de ancestral tradición hispánica.

${ }^{43}$ Le Horla 2, p. 914.

${ }^{44}$ Ibidem, p. 938.

${ }^{45}$ PB, p. 382.
}

"CUADERNOS DE ESTUDIOS GALLEGOS", Tomo XLI, Fascículo 106, Santiago 1993-94. 
asunto fantástico es mucho más superficial en la pluma de la escritora gallega. No obstante, cabe señalar en su descargo que Maupassant estaba especialmente dotado para narrar el proceso de comprehensión de lo que le ocurre a su personaje por haber sufrido $-\mathrm{y}$, al cabo, enloquecido por su causa - alucinaciones sensoriales, sobre todo visuales, que, a pesar de todo, no le impidieron mantener alerta su percepción intelectual de las mismas.

Doña Emilia manifestó en varios lugares de su obra la admiración que sentía por el creador de Boule de suif, al que gustaba de llamar "Guido de Maupassant" ${ }^{\prime 46}$. En sus estudios sobre este autor subraya la presencia de lo regional normando así como su condición de enfermo mental:

"su literatura —dice—, ya pesimista, estuvo desde mucho más atrás de lo que se adivinó, infiltrada de los negros presentimientos, los terrores vagos, las aprensiones que sufre un cerebro al borde de la lesión cerebral ${ }^{\prime \prime 47}$.

Elogia con pasión la pulcritud de su prosa, siempre contenida y agudamente precisa:

"La ejecución impecable, su naturalidad, lo genuino del léxico, la sencillez de los medios y recursos, la maestría de la composición, la sobriedad en el estilo" ${ }^{\prime \prime 8}$.

En los relatos de Maupassant vistos hasta ahora hemos tenido ocasión de apreciar otra de las características que Pardo Bazán atribuye en alto grado al autor normando: su objetividad. Tanto en sus cuentos como en sus novelas cortas - Le Horla $2 \mathrm{es,} \mathrm{de} \mathrm{hecho,} \mathrm{una} \mathrm{nouvelle} \mathrm{stricto} \mathrm{sensu-}$ se hace patente la observación impasible, como quería su amigo Flaubert. Pardo Bazán no cumple la premisa de la objetividad de manera rigurosa, como hemos visto, aunque intenta, por medio del narrador en primera persona, cubrirse las espaldas y evitar así que el autor implícito deje su impronta en el relato y lo tiña con su onerosa subjetividad.

De igual modo, en los cuentos analizados es visible el recuerdo que hemos llamado temático de Maupassant; desde la megalomanía de don Probo Gutiérrez hasta el análisis de la causa del suicidio de Federico Molina

\footnotetext{
${ }^{46}$ Cfr. Pardo Bazán, Emilia, La literatura francesa moderna, El Naturalismo, OC, Tomo XLI, Madrid, Renacimiento, h. 1914, Capítulo IV: "El cuento", pp. 149-169.

${ }^{47}$ Ibidem, p. 162.

${ }^{48}$ Ibidem, p. 163.
}

"CUADERNOS DE ESTUDIOS GALLEGOS", Tomo XLI, Fascículo 106, Santiago 1993-94. 
los cuentos pardobazanianos responden inequívocamente a la presencia obsesiva de estos dos grandes temas en las creaciones de Maupassant $t^{49}$. El autor que, ya desde 1876 en el poema titulado Terreur, percibía la presencia insidiosa e ineluctable de "quelqu'un qui se tenait debout derrière moi".

${ }^{49}$ Vid. CLEMESSY, Nelly, "Emilia Pardo Bazán et le conte fantastique", Mélanges à la mémoire d'André Joucla-Ruau, Université de Provence, 1978, Tome I, pp. 565-575. En este trabajo N. Clémessy es categórica (p. 574):

"Il s'agit d'Eximente dont l'inspiration semble de toute évidence empruntée à Le Horla de Maupassant".

"CUADERNOS DE ESTUDIOS GALLEGOS", Tomo XLI, Fascículo 106, Santiago 1993-94. 